\title{
Internet y nuevas tecnologías como punta de lanza para la revitalización de territorios rurales despoblados. La necesaria reconstrucción de la idea de servicio público
}

José Luis Domínguez Álvarez ${ }^{1}$

\section{RESUMEN}

Las nuevas tecnologías representan una oportunidad sin precedentes para revitalizar las áreas rurales despobladas, visibilizar la importancia capital de garantizar el acceso a la población a unos servicios esenciales de calidad, y enfatizar la relevancia que las comunidades rurales juegan en nuestra sociedad. Para lograr el despliegue de todas estas potencialidades derivadas del avance de la digitalización y datificación de la sociedad, es preciso poner fin a la desconexión tecnológica que padecen los territorios rurales despoblados,

1 Máster Universitario en Gestión Administrativa de la Universidad de Salamanca, Salamanca, España. Personal Investigador en Formación (FPU17/01088) del Área de Derecho Administrativo de la Universidad de Salamanca, Salamanca, España.Correo-e: jldoal@ usal.es. Enlace ORCID: https://orcid.org/0000-0002-7623-8029. Fecha de recepción: 15 de enero de 2021. Fecha de modificación: 30 de abril de 2021. Fecha de aceptación: 10 de mayo de 2021. Para citar el artículo: Domínguez Álvarez, José Luis, "Internet y nuevas tecnologías como punta de lanza para la revitalización de territorios rurales despoblados. La necesaria reconstrucción de la idea de servicio público", Revista digital de Derecho Administrativo, Universidad Externado de Colombia, n. ${ }^{\circ}$ 26, 2021, pp. 91-124. DOI: https://doi.org/10.18601/21452946.n26.04. 
problemática en la que la actividad prestacional de las Administraciones públicas y la institución del servicio universal adquieren una dimensión decisiva, y a cuyo estudio se dedican las siguientes páginas.

Palabras clave: comunidades rurales, telecomunicaciones, servicio público, obligaciones de servicio universal, desconexión digital.

\section{Internet and New Technologies as a Driving Force for the Revitalization of Unpopulated Rural Territories. The Necessary Reconstruction of the Idea of Public Service}

\section{ABSTRACT}

New technologies represent an unprecedented opportunity to revitalize depopulated rural areas, make visible the vital importance of guaranteeing the population's access to quality essential services, and emphasize the relevance that rural communities play in our society. In order to achieve the deployment of all these potentialities resulting from the advance of digitalization and datafication of society, it is necessary to put an end to the technological disconnection suffered by depopulated rural territories, a problem that requires the involvement of public administrations to ensure compliance with the mandate of universal service.

Keywords: Rural Communities, Telecommunications, Public Service, Universal Service Obligations, Digital Disconnection.

\section{INTRODUCCIÓN}

En los últimos años, la minoración de la actividad prestacional de las Administraciones públicas y la paulatina desaparición de servicios esenciales en las áreas rurales de la geografía española, también conocida como España vaciada ${ }^{2}$, ha sido una constante.

Fruto de esta problemática, el 31 de marzo de 2019, una muchedumbre procedente de las diferentes latitudes del Estado español irrumpió en las calles de Madrid con la finalidad de denunciar, pancarta en mano, la constante

2 Nomenclatura que emana de la afortunada síntesis que da nombre al libro de SERGIO DEL Molino, La España vacía: Viaje por un país que nunca fue, Madrid: Turner, 2016. 
discriminación y el abandono al que los poderes públicos habían sometido durante décadas a la España rural, frente a otra España que crece, prospera y concentra la práctica totalidad de los recursos, prestaciones e inversiones públicas. Surge así la Revuelta de la España Vaciada, un movimiento capaz de visibilizar el hartazgo de la población rural y de transformar el sentimiento de agonía ${ }^{3}$ y apatía latente en la mayor parte de los municipios rurales despoblados, en una ola de esperanza, inconformismo y anhelos de cambio necesario para revitalizar este preciado entorno ${ }^{4}$.

No obstante, conviene subrayar que esta problemática que atraviesan las áreas escasamente pobladas de la Península Ibérica, se extiende igualmente por buena parte de los Estados del sur de Europa sin aparente solución de continuidad, amenazando la pervivencia de las comunidades rurales y afectando de forma nuclear al pleno ejercicio de los derechos y libertades fundamentales de quienes habitan en el medio rural. Ante esta tesitura urge preconizar el protagonismo que el ordenamiento jurídico, y especialmente el derecho administrativo, posee en la articulación de respuestas normativas que permitan incrementar la esfera vital de la población y revertir los procesos de abandono de los territorios rurales, algo que se hace especialmente palpable en el supuesto concreto de la provisión de servicios públicos en el medio rural como presupuesto indispensable para combatir la despoblación.

En efecto, el artículo 174 TFUE pone de manifiesto la necesidad de prestar especial atención a los territorios escasamente poblados en los siguientes términos: "A fin de promover un desarrollo armonioso del conjunto de la Unión, esta desarrollará y proseguirá su acción encaminada a reforzar su cohesión económica, social y territorial. La Unión se propondrá, en particular, reducir las diferencias entre los niveles de desarrollo de las diversas regiones

3 Desde 2001 hasta 2018 han perdido población el 63 \% de los municipios españoles. La intensidad de las tasas de variación poblacional 2018-2001 por municipios, muestran que el $48,1 \%$ de los municipios han perdido entre el $10 \%$ y el $50 \%$ de la población. Y si nos centramos en la última década, desde 2011, 6.516 municipios están perdiendo población, es decir, el 80,2 \% de nuestros municipios. En los pequeños municipios, las pérdidas afectan a casi el $90 \%$ de los menores de 1.000 habitantes. Si a esto le añadimos que el $48,4 \%$ de los municipios españoles está por debajo de 12,5 habitantes por $\mathrm{km}^{2}$, ratio que la Unión Europea califica como de riesgo de despoblación (de ese 48,4 \%, el $83,5 \%$ son municipios de menos de 500 habitantes) obtenemos una foto fija alarmante de la problemática que padecen las áreas rurales. Véase COMISIONADO DEL GOBIERNO Frente al Reto Demográfico, Directrices generales de la Estrategia Nacional Frente al Reto Demográfico, Madrid: CGFRD, 2019, p. 6.

4 El 31 de marzo de 2021 se cumplió el segundo aniversario de la manifestación que tuvo lugar en Madrid y que congrego a decenas de plataformas ciudadanas de la "España Vaciada" (EVA), llenando las calles de la ciudad con cerca de 100.000 personas que, como sociedad civil, denunciaban la situación de discriminación y abandono en la que los poderes públicos han sumergido al medio rural. 
y el retraso de las regiones menos favorecidas. Entre las regiones afectadas se prestará especial atención a las zonas rurales, a las zonas afectadas por una transición industrial y a las regiones que padecen desventajas naturales o demográficas graves y permanentes, como, por ejemplo, las regiones más septentrionales con una escasa densidad de población y las regiones insulares, transfronterizas y de montaña".

Más específicamente, el artículo 175 TFUE señala que "los Estados miembros conducirán su política económica y la coordinarán con miras a alcanzar también los objetivos enunciados en el artículo 174".

Por su parte, la Constitución española contiene un modelo cuya amplia formulación, permite albergar opciones variadas de política económica: el progreso económico (artículos 40.1. 130.1 y 131.1); el principio de igualdad en sus dos vertientes de equilibrio entre espacios territoriales (artículos 138 y 158) y de nivelación de rentas personales (artículos 130, 131.1 y 140.1); la unidad de mercado (artículo 139.2); la estabilidad económica (artículo 140.1), la productividad (artículo 38), etc. Entre todas las técnicas o instrumentos puestos al servicio de estos principios inspiradores, reviste especial importancia el previsto en el artículo 128.2 CE, a cuyo tenor "se reconoce la iniciativa pública en la actividad económica. Mediante ley se podrá reservar al sector público recursos o servicios esenciales, especialmente en caso de monopolio y asimismo acordar la intervención de empresas cuando así lo exigiere el interés general", lo que supone de facto la admisión de la eventual participación de la Administración en la vida económica, orientando en un sentido u otro la producción de bienes o la prestación de servicios ${ }^{5}$.

Ante esta tesitura, el Consejo de Ministros aprobó, con fecha 29 de marzo de 2019, un importante Acuerdo sobre las Directrices Generales de la Estrategia Nacional frente al Reto Demográfico, elaboradas por el Comisionado del Gobierno frente al Reto Demográfico ${ }^{6}$, adscrito al Ministerio de Política Territorial y Función Pública.

Las Directrices Generales de la Estrategia Nacional frente al Reto Demográfico se fundamentan en las tres cuestiones demográficas acordadas en la IV Conferencia de Presidentes ${ }^{7}$ : despoblación, envejecimiento y efectos de

5 Véase Francisco Sosa Wagner, La gestión de los servicios públicos locales. 7. ${ }^{a}$ ed., Madrid: Civitas, 2008, p. 28.

6 En este sentido, recuérdese que el Gobierno de España aprobó el Real Decreto 40/2017, de 27 de enero, por el que se crea el comisionado del Gobierno frente al Reto Demográfico y se regula su régimen de funcionamiento, y al que corresponde la elaboración y el desarrollo de una estrategia nacional frente al reto demográfico y aquellas tareas que contribuyan a dar respuesta a la problemática del progresivo envejecimiento poblacional, del despoblamiento territorial y de los efectos de la población flotante.

$7 \quad$ El presidente del gobierno y los presidentes de comunidades autónomas y ciudades con estatuto de autonomía convinieron en la vi Conferencia de Presidentes, celebrada 
la población flotante; estableciendo un conglomerado de más de ochenta medidas, referidas a jóvenes, mujeres, atención a la población rural, emprendedores, servicios públicos, turismo, implantación de la Administración en el territorio o actividad económica.

Dichas actuaciones se agrupan en torno a siete grandes objetivos transversales, dos de los cuales están estrechamente imbricados con nuestro objeto de estudio: garantizar una plena conectividad territorial, con una adecuada cobertura de internet de banda ancha y de telefonía móvil en todo el territorio, de conformidad con los postulados de la Agenda Digital Europea 2020; y asegurar una apropiada prestación de servicios básicos a toda la población en condiciones de equidad.

En torno a esta cuestión, es necesario recordar que, como han puesto de relieve de forma reiterada y continuada en el tiempo las diferentes instituciones europeas ${ }^{8}$, las zonas rurales padecen una falta de acceso generalizado a las tecnologías de la información y la comunicación, lo que repercute negativamente en sus posibilidades de crecimiento económico y demográfico ${ }^{9}$.

el 17 de enero de 2017, afrontar los cambios demográficos que afectan a España y, de forma concreta, acordaron las siguientes cuestiones: "1. Impulsar medidas específicas para hacer frente a los desafíos demográficos. 2. Elaborar y desarrollar, por parte del Gobierno de España, y contando con la colaboración de las Comunidades Autónomas, las Ciudades con Estatuto de Autonomía y las Entidades Locales, una Estrategia Nacional frente al Reto Demográfico, de naturaleza global y transversal, que diseñe una respuesta conjunta y de futuro para paliar la problemática del progresivo envejecimiento poblacional, del despoblamiento territorial y de los efectos de la población flotante. 3. En dicha Estrategia, que debería estar aprobada en 2017, habrán de ser consideradas las conclusiones y recomendaciones de la Ponencia de estudio para la adopción de medidas en relación con la despoblación rural en España (creada en el seno de la Comisión de Entidades Locales del Senado), las propuestas y recomendaciones de la Comisión Especial de Estudio del Senado sobre las medidas a desarrollar para evitar la despoblación de las zonas de montaña y, en su momento, las que emanen de la Comisión Especial de Estudio sobre la evolución demográfica. Y tendrá también en cuenta los trabajos del Foro de Regiones españolas con Desafíos Demográficos (FREDD) y el dictamen del Comité de las Regiones, así como aquellos otros que puedan aportar las distintas Administraciones autonómicas. 4. El Gobierno de España, las Comunidades Autónomas y las Ciudades con Estatuto de Autonomía, en la medida de sus posibilidades, defenderán ante las autoridades de la Unión Europea la necesidad de que las políticas de la Unión tengan en cuenta y den respuesta a los desafíos demográficos, que en la mayoría de los aspectos son comunes a todos los Estados miembros".

8 Una clara manifestación de esta tendencia la encontramos en la Declaración de Venhorst, formulada por el Parlamento Europeo en 2017 con el propósito de promover la cooperación entre los diferentes Estados miembros en ámbitos esenciales para las áreas rurales tales como la conectividad, las infraestructuras, los servicios, el refuerzo de las economías locales y la lucha contra la pobreza y la exclusión social.

9 Véase Comisión EuROPEA, Mejorar el acceso de las zonas rurales a las modernas tecnologías de la información y la comunicación (TIC) [COM(2009) 103 final]. 
Con la finalidad de revertir esta perniciosa tendencia, conviene no solamente adoptar instrumentos de planificación y programación en el seno de las diferentes instituciones, sino también, y lo que es más importante, clarificar la incidencia que la actividad prestacional de las Administraciones públicas y la vigente regulación comunitaria de los servicios de interés económico general poseen en los procesos de abandono de las áreas rurales del sur de Europa ${ }^{10}$.

Sentado lo anterior, el presente artículo focaliza su atención en cuatro aspectos esenciales: (1) determinar el grado de desconexión digital que existe en las áreas rurales que conforman la España vaciada ${ }_{i}(2)$ analizar el impacto que la regulación actual de las telecomunicaciones presenta en la extensión de la sociedad en red en los territorios escasamente poblados; (3) comprobar la efectividad y eficacia que posee la imposición de obligaciones de servicio universal a los grandes prestadores de servicios digitales en el marco de la concepción europeísta de los servicios de interés económico general ${ }_{i}$ (4) examinar las connotaciones que plantea el advenimiento del Estado garante ante el posible incumplimiento de las obligaciones de servicio público y servicio universal ${ }_{i}$ y (5) esbozar una serie de ideas acerca de las ventajas y potencialidades que presenta la reconstrucción de la idea de servicio público larvada en los antiguos postulados de la Escuela de Burdeos.

Con la finalidad de despejar todas estos interrogantes, el estudio procede a la consulta de cuantiosos informes, estudios y documentos de posicionamiento de diferentes instituciones, nacionales y comunitarias, los cuales permiten dibujar una panorámica completa que evidencia las dificultades que experimentan los territorios rurales escasamente poblados a la hora de acceder a las nuevas tecnologías, al tiempo que se emprende una prolija travesía por algunas de las obras más relevantes de la doctrina iuspublicista encargadas de analizar la actividad prestacional de las Administraciones públicas. Se trata, en definitiva, de transitar desde los vetustos postulados del servicio público alumbrados por DUGuiT y la Escuela de Burdeos, hasta la consolidación de la teoría europeísta de los servicios de interés general imperante en nuestros días. Todo ello con el firme propósito de esbozar una serie de ideas que permitan, por un lado, clarificar la efectividad que posee

10 Las regiones rurales representan la mitad de Europa y aglutinan alrededor del $20 \%$ de su población. Sin embargo, la mayor parte de estas zonas rurales figuran entre las regiones menos favorecidas de la Unión Europea, con un PIB per cápita muy por debajo de la media comunitaria. Recientemente, la Comisión Europea ha publicado el informe Impacto del cambio demográfico en Europa, en el que se establecen las repercusiones del cambio demográfico en toda Europa, pero también pone en marcha un proceso que ayudará a identificar acciones y soluciones concretas para apoyar a las personas, regiones y comunidades más afectadas, y permitirles adaptarse a las realidades cambiantes. Los pasos siguientes de este proceso incluyen un libro verde sobre el envejecimiento y una comunicación de la Comisión sobre la visión a largo plazo para las zonas rurales que se publicarán en 2021 
la imposición de obligaciones de servicio universal y, por otro, combatir la inacción de las Administraciones públicas en la materia al objeto de garantizar el despliegue de las telecomunicaciones en las áreas escasamente pobladas, conscientes de que las nuevas tecnologías son un factor decisivo a la hora de devolver el alma a los territorios y comunidades rurales.

\section{LA DESCONEXIÓN DIGITAL DE LAS ÁREAS RURALES: ¿UN DESAFÍO INSALVABLE?}

Las nuevas tecnologías disponen de una importancia trascendental para favorecer el asentamiento y la fijación de población en el medio rural, tal y como se desprende de las Directrices Generales de la Estrategia Nacional frente al Reto Demográfico, aprobadas por el Consejo de Ministros en su sesión de 29 de marzo de $2019^{[11]}$. No obstante, conviene recordar que en las últimas décadas las zonas rurales que pueblan la geografía española han visto como la (i)lógica economía de mercado ${ }^{12}$ y el capitalismo depredador de recursos naturales y generador de grandes desigualdades ${ }^{13}$, unido a la existencia de una normativa administrativa desmedida, el acusado intervencionismo al que las Administraciones públicas someten cualquier iniciativa vital en el medio rural, o la desaparición progresiva de los servicios públicos básicos -imprescindibles para garantizar unos estándares mínimos de bienestar y calidad de vida-, han puesto en seria duda la pervivencia de las comunidades rurales ${ }^{14}$.

Sin embargo, la irrupción de la COVID-19 ha propiciado el surgimiento de multitud de transformaciones de profundo calado, las cuales rebasan la esfera puramente sanitaria, impulsando importantes cambios socioeconómicos, entre los que destaca por su extraordinaria importancia la evolución de las formas tradicionales de intervención administrativa o el empoderamiento o aceleración de los avances derivados de la (r)evolución digital, cuestión que abre una nueva ventana de oportunidades para la revitalización de las áreas

11 Véase Comisionado del Gobierno Frente al Reto Demográfico, Directrices generales de la Estrategia Nacional frente al Reto Demográfico.

12 Véase Alfonso Buenaventura Calvo y José Luis Domínguez Álvarez, "¿Reinventarse o morir? El municipalismo como piedra angular del anhelado desarrollo rural sostenible. San Martín del Castañar, una referencia al sur de la provincia de Salamanca". En Marcos Matías Fernando Pablo y José Luis Domínguez Álvarez (Dirs.), Rural Renaissance: Derecho y medio rural, Cizur Menor: Thomson Reuters-Aranzadi, 2020, p. 145.

13 Véase Luis del Romero Renau, Despoblación y abandono de la España rural: El imposible vencido, Valencia: Tirant Humanidades, 2018, p. 18.

14 Véase José Luis Domínguez Álvarez, Comunidades discriminadas y territorios rurales abandonados. Políticas públicas y derecho administrativo frente a la despoblación, Cizur Menor: Thomson Reuters, 2021, pp. 35 y ss. 
rurales despobladas. Una clara manifestación de esta tendencia la encontramos en el auge del teletrabajo y la llegada de nuevos pobladores, también conocidos como "nómadas digitales", los cuales han encontrado en las áreas rurales, por lo general, un reducto espacial seguro y resiliente, alejado de los avatares provocados por la pandemia sanitaria.

En este difícil contexto, es preciso clarificar el pernicioso impacto que la desconexión digita $1^{15}$, latente en la mayor parte del medio rural español ${ }^{16}$, posee en el despliegue del teletrabajo en el horizonte post COVID-19, así como esbozar una serie de propuestas innovadoras desde el prisma del derecho administrativo, las cuales dependen, en gran medida, de la correcta aplicación de la teoría de los servicios de interés general (SIG) ${ }^{17}$, tesis que impera en la ordenación normativa de la actividad prestacional de las Administraciones públicas desde la última década del siglo XX.

Ahora bien, chasta qué punto el teletrabajo ${ }^{18}$ puede considerarse un fenómeno novedoso capaz de revertir la diáspora demográfica del medio rural? ¿Es la reciente regulación de este fenómeno laboral un hito suficiente para remover los obstáculos que impedían el despliegue de esta forma de organización del trabajo en la España rural?

15 En este punto, conviene señalar que "la digitalización del medio rural, es decir, la incorporación efectiva, extendida y compartida de las tecnologías de la información y la comunicación en todo el territorio, es un elemento clave para luchar contra la despoblación. Existen numerosos ejemplos y buenas prácticas con acciones y proyectos compartibles y replicables. La mayoría se centran en mejorar la producción agraria, ganadera y forestal, pero no se pierde de vista la formación, el teletrabajo, la mejora de los servicios sociales y el afianzamiento de mujeres y jóvenes en el territorio". Véase JaVier Rico Nieto, "La digitalización es una pieza clave en la lucha contra la despoblación", Desarrollo Rural y Sostenible, n. ${ }^{\circ} 43,2020$, p. 14

16 Según datos facilitados por el Instituto Nacional de Estadística (INE), en las comunidades autónomas de Galicia, Castilla y León, Extremadura, Castilla-la Mancha y Andalucía, el porcentaje de hogares desconectados se sitúa por encima del $10 \%$, lo que supone un importante número de familias carentes de internet en las zonas rurales. Véase InStituto Nacional de Estadística, Encuesta sobre Equipamiento y Uso de Tecnologías de Información y Comunicación en los Hogares 2019, Madrid, 2020. Disponible en https://bit. ly/2VSbxEO [consultado el 27 de enero de 2021].

17 La nueva doctrina de la Unión Europea sobre los servicios de interés general, cuyas bases se hallan en sucesivos documentos de la Comisión sobre los Servicios de Interés General en Europa (Comunicaciones de 1996 y 2001, Libro Verde de 2003, el Libro Blanco de 2004 y la Comunicación de 20 de noviembre de 2007), determina que los servicios de interés general constituyen un elemento esencial del modelo europeo de sociedad, parte de los valores compartidos por todas las sociedades europeas y uno de los pilares de la sociedad europea.

18 Véase José Luis DomíngueZ ÁlvareZ, "El impulso del teletrabajo en la España vacia(da) en la era post COVID-19: Del mito al logos". En Juan Francisco Rodríguez Ayuso y Elena Atienza Matías (coords.), El nuevo marco legal del teletrabajo en España: Presente y futuro, una aproximación multidisciplinar, Madrid: Wolters Kluwer, 2021, pp. 389 y ss. 
En lo que se refiere a la primera cuestión, el teletrabajo ${ }^{19}$, es decir, "aquel trabajo a distancia que se lleva a cabo mediante el uso exclusivo o prevalente de medios y sistemas informáticos, telemáticos y de telecomunicación ${ }^{\prime 20}$ no representa, en sí mismo, una alternativa novedosa o singular para revertir los procesos de abandono de las áreas rurales ${ }^{21}$.

Ciertamente, cuando nos referimos al teletrabajo como palanca transformadora de la realidad rural, estamos haciendo alusión a una alternativa cierta para dinamizar la economía de las áreas rurales, fomentar nuevas formas de empleabilidad y asentar población de forma efectiva en el medio rural, cuestiones todas ellas esenciales para alcanzar el anhelado desarrollo rural sostenible y avanzar en la conquista de un nuevo modelo de organización del territorio, más justo, equilibrado e igualitario. Sin embargo, este discurso posibilista colisiona frontalmente con la realidad de la España rural, como

19 Una de las primeras definiciones del teletrabajo la encontramos en un informe de la Comisión Europea, el cual ya en el año 1995 conceptualizaba este fenómeno de la siguiente forma: "La palabra 'teletrabajo' designa aquellas actividades ejercidas lejos de la sede de la empresa (se le denomina también en ocasiones trabajo a distancia), a través de la comunicación diferida o directa por medio de las nuevas tecnologías". Cfr. ComISIÓN EUROPEA, Le travail à domicile dans l'Union Européenne. Rapport du groupe de travail ad boc, Bruselas: Comisión Europea, 1995. Una definición más prolija, fechada en el idéntico horizonte temporal, la encontramos en la obra El teletrabajo, cuyos autores conciben como "una forma flexible de organización del trabajo, que consiste en el desempeño de la actividad profesional sin la presencia física del trabajador en la empresa durante una parte importante de su horario laboral. Engloba una amplia gama de actividades y puede realizarse a tiempo completo o parcial. La actividad profesional en el teletrabajo implica el uso frecuente de métodos de procesamiento electrónico de información, y el uso permanente de algún medio de telecomunicación para el contacto entre el trabajador y la empresa". Véase MiKe Gray, NOel Hodson y Gil Gordon, El teletrabajo, Madrid: BT Telecomunicaciones-ECTF-Fundación Universidad Empresa, 1995.

20 Véase artículo 2 del Real Decreto-Ley 28/2020, de 22 de septiembre, de trabajo a distancia.

21 Son muchos los teóricos y académicos que subrayan, desde hace décadas, las ventajas y potencialidades que el impulso del teletrabajo representa para las áreas rurales despobladas. En este sentido, hace una década Buirá Ciprés afirmaba lo siguiente: "Sin duda la introducción del teletrabajo en los pueblos impediría en alguna medida las migraciones laborales y evitaría efectos sobre la población rural (despoblamiento de jóvenes, envejecimiento de la población, etc.). En cierto modo tendería a 'fijar en el territorio' a los futuros trabajadores de los nuevos trabajos que se podrían crear y asimismo acogería a las nuevas profesiones. Teóricamente, el teletrabajo podría tener consecuencias apreciables de tipo económico y sociológico para las comarcas rurales, que contrarrestarían los efectos negativos que se presume podían aparecer con el advenimiento de la sociedad de la información y el futuro trabajo sobre el conocimiento". Véase Jordi BuIRÁ CiPRÉS, El teletrabajo. Entre el mito y la realidad, Barcelona: Ediciones Universitat Oberta de Catalunya, 2012, p. 59. 
atestiguan la infinidad de propuestas académicas ${ }^{22}$ que, desde hace más de una década, abogan por el impulso de esta modalidad laboral como respuesta a la sangría poblacional que padece la España vacia $(\mathrm{da})^{23}$.

Entre las causas que se esconden tras la escasa y dificultosa implementación del teletrabajo en la España rural, sobresalen por su especial relevancia los desequilibrios latentes en la prestación de servicios públicos esenciales (transporte, conectividad a internet, telefonía móvil, etc.), los cuales, como hemos señalado con anterioridad, privados de la masa crítica de demanda imprescindible para rentabilizar su mantenimiento, han terminado por añadir un nuevo y decisivo factor que no solamente acelera el abandono de las áreas rurales, sino que además imposibilita el asentamiento de nuevos pobladores que permitan equilibrar el saldo demográfico de este preciado entorno ${ }^{24}$. Esta y otras muchas cuestiones, unida a la inacción de las diferentes instituciones y poderes públicos ${ }^{25}$ han propiciado que aún en nuestros días, el teletrabajo en

22 Ciertamente, son muchos los académicos que, de forma acertada, rompen una lanza en favor del impulso del teletrabajo como estrategia para devolver el alma a los pueblos de la España despoblada. Cfr. Asunción Blanco Romero y Gemma CánOves VALIENTE, "El teletrabajo, calternativa para el mundo rural?", en IX Coloquio de Geografía Rural: Comunicaciones, Vitoria: Universidad del País Vasco, Departamento de Geografía, Prehistoria y Arqueología, 1998, pp. 57-62, Gemma CÁnOVES VAliente y Asunción Blanco Romero, "Teletrabajo, género y gentrificación o elitización en los espacios rurales: Nuevos usos y nuevos protagonistas. Los casos de Cataluña y Ardèche (Francia)". Geograpbicalia, n. ${ }^{\circ}$ 50, 2006, pp. 27-44; ANTONIO COlOM GORGUES, "Innovación organizacional y domesticación de internet y las TIC en el mundo rural, con nuevas utilidades colectivas y sociales. La figura del telecentro y el teletrabajo", Ciriec España, n. ${ }^{\circ}$ 49, 2004, pp. 77-116; ROSARIO SAMPEDRO GALLEGO, "Conciliación de la vida familiar y laboral en el medio rural: género, trabajo invisible e 'idilio rural'". En Mujeres rurales: Estudios multidisciplinares de género. Salamanca: Ediciones Universidad de Salamanca, 2014, pp. 81-94, etc.

23 Como precisa Bello Paredes, el término España vacía y la noción España vaciada representan realidades diferentes, aunque ambas expresiones pueden utilizarse para identificar la situación de alarma por la que atraviesan buena parte de las áreas rurales de la geografía española. En este sentido, según la RAE, mientras que la expresión vacía, en una de sus acepciones, en la que se refiere concretamente a un lugar físico, significa literalmente que: "está con menos gente de la que puede concurrir a él"; la palabra vaciada es contemplada como el resultado de una acción de vaciar. Véase SANTIAGO Agustín Bello Paredes, "Castilla y León vacía (vaciada): Esperando a Ulises". Revista de Estudios de la Administración Local y Autonómica, n. ${ }^{\circ}$ 13, 2020, p. 111.

24 Véase José Luis Domínguez Álvarez, "El agotamiento de las políticas públicas relacionadas con el desarrollo rural", pp. 219-220.

25 Véase José Luis Domínguez Álvarez, "El desigual acceso de la juventud rural a los servicios públicos: La necesidad de impulsar la educación en la España vaciada", Cuadernos de Investigación en Juventud, n. ${ }^{\circ}$ 8, 2020, p. 63. 
la España vacia $(\mathrm{da})^{26}$ se presente como una alternativa de futuro, y no cómo una realidad tangible, útil para dinamizar la economía local y capaz de sentar las bases del modelo de desarrollo territorial sostenible que está por llegar.

Un ejemplo palmario de esta carencia generalizada de servicios esenciales en el medio rural, relacionados íntimamente con el acceso al teletrabajo, lo encontramos en lo que se refiere a los servicios de telecomunicaciones ${ }^{27}$. De conformidad con los datos que publica la Encuesta sobre Equipamiento y Uso de Tecnologías de Información y Comunicación en los Hogares del Instituto Nacional de Estadística, en 2017 un 70,8 \% de los hogares de núcleos de población con menos de 10.000 habitantes ${ }^{28}$ disponía de algún tipo de ordenador, un 76,1 \% tenía acceso a internet y un 75,3 \%, conexión a banda ancha. En las poblaciones de más de 100.000 habitantes y capitales de provincia, dichos porcentajes ascendían al $82,4 \%, 86,1 \%$ y $85,5 \%$, respectivamente ${ }^{29}$.

Esta perniciosa tendencia, contrasta con la importancia capital que reviste garantizar el acceso de la ciudadanía y las empresas a los servicios de telecomunicaciones como presupuesto para corregir el tradicional aislamiento de los núcleos rurales, favoreciendo la cohesión económica y social, así como

26 Como dato estadístico, en el barómetro del Cis de febrero de 2019 (pregunta 24) se afirma que un $82,4 \%$ de los encuestados sí conoce lo que es la despoblación en España y que un $88,5 \%$ lo considera como un problema grave o muy grave $(41,4 \%$ lo considera muy grave y $47,1 \%$ grave).

27 Cfr. Estrella Martín, "El acceso a internet, un servicio obligatorio en todo el medio rural", Vida Rural, n. ${ }^{\circ} 156,2002$, pp. 44-45.

28 Si bien es cierto que, a la vista de la Encuesta sobre Equipamiento y Uso de Tecnologías de Información y Comunicación en los Hogares del Instituto Nacional de Estadística, se observa una evolución positiva hacia la plena conectividad del territorio, conviene subrayar que la brecha digital en los municipios del medio rural sigue perdurando y la realidad es bien distinta. Téngase en cuenta que la encuesta utiliza como referencia aquellos municipios con una población igual o superior a los 10.000 habitantes, algo que choca frontalmente con la dimensión de los municipios que pueblan la realidad rural, los cuales representan la inmensa mayoría en comunidades autónomas como Castilla y León, Extremadura, Castilla-La Mancha o Aragón. Según datos del último informe de Cobertura de Banda Ancha publicado por el Ministerio de Asuntos Económicos y Transformación Digital, un 13,4 \% de las zonas rurales en España no tiene acceso a internet de al menos $30 \mathrm{Mbps}$ de velocidad a través de redes terrestres. Este dato, aunque refleja un avance significativo en la penetración de cobertura en la España rural, no cumple con el objetivo estatal de conectar con internet de banda ancha al $90 \%$ de los ciudadanos de estos núcleos, reto que estaba previsto alcanzar antes del $1 .^{\circ}$ de enero de 2020. Además, esta situación se agrava para 1,82 millones de hogares que apenas puede acceder a una conexión ADSL a 2 Mbps de velocidad, de acuerdo con el mismo estudio.

29 Véase InSTITUTO NaCiOnAL DE EsTAdístiCA, Encuesta sobre Equipamiento y Uso de Tecnologías de Información y Comunicación en los Hogares 2019, Madrid: Instituto Nacional de Estadística, 2020. Recuperado de https://bit.ly/36jshtk [consultado el 20 de enero de 2021]. 
la vertebración del territorio. En este sentido, el Consejo Económico y Social señala que "la utilización de internet, especialmente a través de la banda ancha, facilita el acceso de la población a la información y a un gran número de servicios, al tiempo que posibilita la comercialización de los productos desde y hacia los núcleos rurales. Disminuye la dependencia de las infraestructuras físicas de transporte, en la medida en que posibilita el comercio electrónico, el desarrollo de la Administración electrónica, la provisión de servicios de salud en línea, la teleformación, o el teletrabajo, contribuyendo, por tanto, a fijar la población. Sin embargo, a pesar de haberse producido importantes avances en este ámbito, continúa existiendo una brecha digital entre las zonas urbanas y rurales. Así, persisten dificultades y carencias en la cobertura y la calidad de los servicios de telecomunicaciones, especialmente en las conexiones de banda ancha (acceso, velocidad y calidad del acceso) y, en menor medida, en la cobertura de la telefonía móvil y en el acceso a los contenidos multimedia de la televisión y la radio" ${ }^{\prime \prime 30}$.

Urge, por tanto, articular una verdadera Estrategia Nacional frente al Reto Demográfico que permita abordar de una forma holística la problemática común que padecen las zonas escasamente pobladas, problemática que transciende los indicadores relativos al envejecimiento de la población rural, y que encuentra en el aislamiento geográfico, las considerables dificultades de integración territorial con otras regiones, la falta de conexiones de transporte y de internet ${ }^{31}$, la ausencia de servicios sociales adecuados, las menores dotaciones de capital humano y oportunidades de empleo, sus principales caballos de batalla.

Sentado lo anterior, y en lo que se refiere a la segunda de las incógnitas que planteábamos con anterioridad, si bien es cierto que la adopción del Real Decreto-Ley 28/2020, de 22 de septiembre, de trabajo a distancia representa un paso decisivo en la implementación de esta nueva modalidad laboral ${ }^{32}$, de la cual se espera un incremento exponencial en los próximos

30 Véase CONSEJO ECONÓMICO Y SOCIAL, El medio rural y su vertebración social y territorial Informe 01/2018, aprobado en sesión ordinaria del Pleno de 24 de enero de 2018, Madrid, 2018, p. 151.

31 Entre el conjunto de medidas prioritarias articuladas en el Plan España Digital 2025 se contempla el siguiente objetivo: "Garantizar una conectividad digital adecuada para el $100 \%$ de la población, promoviendo la desaparición de la brecha digital entre zonas rurales y urbanas (meta 2025: 100 \% de la población con cobertura $100 \mathrm{Mbps)".}$

32 El presente estudio no tiene por objeto defender la generalización del teletrabajo como forma laboral preferente o prioritaria, sino esbozar una serie de propuestas que permitan garantizar el acceso al mismo en condiciones de igualdad al conjunto de trabajadores, evitando con ello la acentuación de las diferencias existentes entre las áreas urbanas y el medio rural. En este punto conviene subrayar que el impulso del teletrabajo plantea una serie de importantes interrogantes desde la óptica de la garantía de los derechos laborales, y especialmente desde la perspectiva de los nuevos derechos digitales, a la 
años $^{33}$, conforme al avance de los crecientes procesos de digitalización y datificación de la sociedad ${ }^{34}$, lo cierto es que, en solitario, este instrumento normativo es insuficiente para afrontar la despoblación de las áreas rurales y garantizar el acceso de la población rural al teletrabajo, premisa que se recoge hasta en tres ocasiones en la exposición de motivos del citado texto.

En nuestra opinión, esta cuestión, garantizar el acceso al teletrabajo de la población en condiciones de igualdad, independientemente del lugar de residencia, posibilidad de la que en la actualidad carece la mayor parte de la población que habita en el medio rural, es una arista más del agotamiento de un modelo de desarrollo territorial injusto y desigual que requiere soluciones jurídico-administrativas ${ }^{35}$ urgentes orientadas a la consecución de dos de los siete objetivos trasversales que conforman las Directrices Generales de la Estrategia Nacional frente al Reto Demográfico:

- Garantizar una plena conectividad territorial, con una adecuada cobertura de internet de banda ancha y de telefonía móvil en todo el territorio, de acuerdo con la Agenda Digital Europea 2020.

luz del título X de la Ley Orgánica 3/2018, de 5 de diciembre, de protección de datos personales y garantía de los derechos digitales. En torno a esta cuestión, cfr. CRISTÓBAL Molina NAVARRETE, "Jornada laboral y tecnologías de la infocomunicación: "Desconexión digital", garantía del derecho al descanso", Temas Laborales, n. ${ }^{\circ} 138,2017$, pp. 254 y ss.; EDUARDO TALÉNS VISCONTI, "La desconexión digital en el ámbito laboral: Un deber empresarial y una nueva oportunidad de cambio para la negociación colectiva", Revista de Información Laboral, n. ${ }^{\circ}$ 4, 2018, pp. 2-12; JUAN ANTONIO AlTÉS TÁRREGA y Sergio Yagüe Blanco, "A vueltas con la desconexión digital: Eficacia y garantías de lege lata", Revista de Derecho del Trabajo y Protección Social, vol. 1, n. ${ }^{\circ} 2,2020$, pp. 61-87; CARLOTA MARÍA Ruíz GONZÁLEZ, "La desconexión digital como garantía y herramienta de conclusión de la jornada laboral. Su necesaria concreción en tiempos de COVID-19", Revista General de Derecho del Trabajo y de la Seguridad Social, n. ${ }^{\circ}$ 56, 2020, etc.

33 Recientemente se ha adoptado el Real Decreto-Ley 29/2020, de 29 de septiembre, de medidas urgentes en materia de teletrabajo en las Administraciones públicas y de recursos humanos en el Sistema Nacional de Salud para hacer frente a la crisis sanitaria ocasionada por la COVID-19, cuyo artículo primero introduce una modificación del Texto Refundido de la Ley del Estatuto Básico del Empleado Público, aprobado por Real Decreto Legislativo 5/2015, de 30 de octubre, en la que se contempla una regulación de carácter básico del teletrabajo en las Administraciones públicas.

34 Cfr. Ministerio de Asuntos ECONÓmicos y Transformación Digital, España digital 2025, Madrid, 2020.

35 En este sentido, Fernando Pablo afirma acertadamente que la problemática de la España vaciada es "un problema de personas; un problema de territorios; un problema, en primer lugar, jurídico, pues a ese campo pertenece la regulación de las relaciones no solo entre personas, sino también entre poderes públicos y ciudadanos, y entre personas y medio". Marcos Matías Fernando Pablo, "Devolver el alma a los pueblos: El encuentro Rural Renaissance", Ars Iuris Salmanticensis, vol. 9, n. ${ }^{\circ}$ 2, 2019, p. 12. 
- Asegurar una apropiada prestación de servicios básicos a toda la población en condiciones de equidad, adaptada a las características de cada territorio.

En esta difícil tesitura es donde entra en juego la actividad prestacional de las Administraciones públicas, el derecho administrativo y la concepción de las telecomunicaciones como servicio universal ${ }^{36}$, incluso pese a los múltiples esfuerzos destinados por la Unión Europea a impulsar la liberalización de servicios estratégicos que contribuyeran de manera significativa a acelerar el proceso de integración europea y a catalizar la competitividad de la economía del viejo continente, a cuyo análisis dedicaremos las próximas líneas.

\section{LAS TELECOMUNICACIONES COMO SERVICIO DE INTERÉS ECONÓMICO GENERAL}

Ciertamente, aunque en la actualidad las telecomunicaciones distan enormemente de lo que antaño era un servicio público reservado y monopolístico $^{37}$, conviene subrayar que aún en nuestros días los intereses públicos en liza siguen imprimiendo un intenso carácter regulado que hace de las telecomunicaciones "servicios de interés económico general" ${ }^{\text {"38, }}$ categoría jurídica alumbrada por el derecho comunitario que pretende equilibrar la

36 Como recuerda Fernández Rodríguez, el concepto de servicio público ha experimentado una profunda evolución desde sus consideraciones iniciales a ojos de los grandes teóricos administrativistas franceses, los cuales llegaron a concebirlo como centro de gravedad y objeto único del Estado y del derecho público al definirlo como "toda actividad cuyo cumplimiento debe ser regulado, asegurado y fiscalizado por los gobernantes, porque el cumplimiento de esa actividad es indispensable para la realización y desenvolvimiento de la interdependencia social y de tal naturaleza que no puede ser asegurada completamente más que por la intervención de la fuerza gobernante", hasta la llegada del Acta Única Europea de 1986, con la que se pone en marcha un mercado único sin fronteras interiores en el que las personas, los bienes, los servicios y los capitales son convocados a circular libremente. Véase TOMÁs RAMÓN FERNÁNDEZ RodríGueZ, "Del servicio público a la liberalización desde 1950 hasta hoy", Revista de Administración Pública, n. ${ }^{\circ}$ 150, 1999, pp. 57-58.

37 En este sentido Montero Pascual subraya que "Los servicios de telecomunicaciones, en especial el servicio telefónico, han sido tradicionalmente considerados servicios públicos, y como consecuencia, han sido objeto de un régimen jurídico exorbitante que excluía la competencia al establecerse derechos exclusivos para su explotación, bien directa por las autoridades públicas en la mayor parte de Europa, bien indirecta en España". Véase Juan José MOnTERo PASCUaL, "Las telecomunicaciones: Servicios de interés general", Revista de Derecho de la Unión Europea, n. ${ }^{\circ}$ 7, 2004, p. 235.

38 Cfr. Matilde CaRlón Ruiz, El servicio universal de telecomunicaciones, Cizur Menor: Thomson-Civitas, 2007. 
tensión entre el interés público y los intereses privados que se concitan en este tipo de actividades económicas. Equilibrio que, por otro lado, implica reconocer rasgos de esencialidad en estas prestaciones respecto de las necesidades de los ciudadanos y que se traduce, principalmente, en un conjunto de limitaciones y de obligaciones para los operadores, entre las que destacan la prestación de "obligaciones de servicio público" y la garantía de un "servicio universal" 39 . De la vigencia y efectividad de estas obligaciones de servicio universal dependerá, en gran medida, la extensión de los servicios digitales en las áreas rurales, y con ello el fin de la desconexión tecnológica de la España vacia(da).

\subsection{LA ACTIVIDAD PRESTACIONAL DE LAS ADMINISTRACIONES PÚBLICAS. HACIA LA CONSOLIDACIÓN DEL ESTADO \\ GARANTE Y SU IMPORTANCIA PARA EL MEDIO RURAL}

La noción de servicio público no es precisamente unívoca ${ }^{40}$ ni tiene perfiles claramente delimitados en nuestro derecho ${ }^{41}$, ya que se utiliza con significa$\operatorname{dos}^{42}$ diferentes en la legislación y en la jurisprudencia. También la doctrina jurídica mantiene posiciones encontradas, fruto de su origen histórico y de la diferente ideología que subyace en la propia noción de servicio público.

Lo podemos definir como un conjunto de actividades regidas total o parcialmente por el derecho administrativo que tienen como objeto ampliar la esfera vital de los ciudadanos. Estos pueden acceder a los servicios públicos cuando cumplan los requisitos y condiciones que establezcan las leyes en cada supuesto concreto ${ }^{43}$.

Realizada una primera y compleja aproximación a la conceptualización del servicio público, conviene adentrarse en otra cuestión neurálgica para entender la regulación jurídico-administrativa de los servicios de

39 Véase Juan Antonio Carrillo Donaire, "El servicio universal de telecomunicaciones", Revista de Administración Pública, n. ${ }^{\circ}$ 179, 2009, pp. 442-443.

40 Véase Luciano Parejo Alfonso, "Servicios públicos y servicios de interés general: La renovada actualidad de los primeros", Revista de Derecho de la Unión Europea, n. ${ }^{\circ}$ 7, 2004, p. 52 .

41 Lo advierte con claridad la Sentencia del Tribunal Supremo, de 23 de mayo de 1997 (RJ 1997/4065): "el concepto de servicio público, calificado frecuentemente de polisémico, no es categoría dogmática unívoca".

42 Por su parte, la Sentencia del Tribunal Supremo, de 24 de octubre de 1989 (RJ 1989/8390), insiste en recalcar que ningún texto legal facilita un concepto de servicio público.

43 En este sentido, Sánchez Morón afirma que "La actividad de servicio público se diferencia de las otras actividades administrativas, como son la de control o policía y la de fomento por su objeto prestacional". MiguEL SÁNCHEZ MORÓn, Derecho administrativo. Parte general, Madrid: Editorial Tecnos, 2018, pp. 767-815. 
telecomunicaciones en la actualidad, y en la que existe un amplio consenso en la doctrina iuspublicista: el carácter mutable del servicio público.

Ciertamente, son muchas las transformaciones que la teoría del servicio público ha sufrido desde su formulación primigenia por parte de la Escuela de Burdeos ${ }^{44}$, para quienes la idea de servicio público representaba no solamente el fundamento y límite del poder público, sino la esencia misma del derecho administrativo ${ }^{45}$. Sin embargo, la configuración del servicio público como una noción amplia que abarca la totalidad de la acción administrativa no ha soportado el paso del tiempo, y el derecho administrativo ha virado su objeto de estudio, pasando a centrar gran parte de sus esfuerzos en el establecimiento de una ordenación que permita subyugar el poder público a la defensa de los derechos y libertades fundamentales de la ciudadanía.

En este contexto se enmarca la catarsis normativa que padece la actividad prestacional de las Administraciones públicas desde la última década del pasado siglo XX. Abrupta transformación que ha estado íntima y estrechamente vinculada a la sucesión de una serie de cambios tecnológicos, económicos, sociales $y$, consecuentemente, políticos que han terminado por trastocar los cimientos del Estado del bienestar en sí mismo. Desde un punto de vista jurídico, el punto de inflexión viene dado por las políticas comunitarias ${ }^{46}$ de signo liberalizador en múltiples sectores económicos ${ }^{47}$. El mejor ejemplo

44 Una aproximación a la concepción del derecho público de Duguit y sus principales aportaciones a la ciencia jurídica, con numerosas referencias, en especial, a la noción de soberanía, la ley como expresión de la voluntad general, el servicio público y la responsabilidad del Estado, así como a la función interventora del Estado y la centralidad de los derechos fundamentales de la persona, puede verse en JAIME RODRíGUEZArana Muñoz, "Sobre Las transformaciones del derecho público de León Duguit", Revista de Administración Pública, n. ${ }^{\circ}$ 190, 2013, pp. 61-100.

45 Para Duguit y su escuela de Burdeos, precisamente el servicio público constituyó el fundamento y límite de la soberanía, el centro neurálgico del derecho público. Véase JAIme RodríGueZ-Arana MuÑoz, "Servicio público y derecho comunitario europeo", A\&C-Revista de Direito Administrativo \& Constitucional, vol. 4, n. ${ }^{\circ}$ 17, 2007, p. 11.

46 La nueva doctrina de la Unión Europea sobre los servicios de interés general, cuyas bases se hallan en sucesivos documentos de la Comisión sobre Servicios de Interés General en Europa (Comunicaciones de 1996 y 2001, Libro Verde de 2003, el Libro Blanco de 2004 y la Comunicación de 20 de noviembre de 2007) determina que los servicios de interés general constituyen un elemento esencial del modelo europeo de sociedad, parte de los valores compartidos por todas las sociedades europeas y uno de los pilares de la sociedad europea.

47 Esta situación política y socioeconómica, caracterizada por la minoración y progresivo adelgazamiento del Estado de bienestar, hasta el estallido de la COVID-19 -la cual ha puesto en jaque incluso los cimientos del proyecto de integración europeo-, ha llevado a importantes autores a sentenciar que las sociedades europeas se enfrentan "a una auténtica ofensiva indiscriminada que, con mayor o menor énfasis, tiende a cuestionar la misma bondad de lo público". MARiAnO BACIGALupo SAGESSE, "El derecho público 
de ello lo constituye la política comunitaria en materia de telecomunicaciones, edificada sobre la base de sucesivos "paquetes" de normas ${ }^{48}$ (particularmente directivas ${ }^{49}$ ).

Obligado por la regulación comunitaria, el legislador español inició un paulatino proceso de introducción de la competencia en un sector, el de las telecomunicaciones, que hasta la fecha había sido concebido como una actividad sometida a titularidad pública por entero. De esta forma, las telecomunicaciones pasan a ser consideradas actividades abiertas a la libre competencia, al tiempo que dejan de ser concebidas como un servicio público stricto sensu tal y como quedaban configuradas en la Ley 31/1987, de 18 de diciembre, de Ordenación de las Telecomunicaciones, y en el siguiente contrato de la Administración General del Estado con Telefónica, de 26 de diciembre de $1991^{[50]}$.

ante la privatización y liberalización de los servicios de interés general: ¿repliegue o transformación?", Boletín de la Facultad de Derecbo de la UNED, n. ${ }^{\circ}$ 16, 2000, p. 159.

48 Véase Matilde CaRlón Ruiz, "El servicio universal de telecomunicaciones", Revista de Administración Pública, n. ${ }^{\circ}$ 171, 2006, p. 37.

49 Este nuevo marco regulador está constituido, como precisa acertadamente Carlón Ruiz, por "cuatro directivas principales, una quinta relativa a la protección de datos y una decisión sobre el espectro radioeléctrico. Concretamente, se trata de la Directiva 2002/21/CE del Parlamento Europeo y del Consejo, de 7 de marzo de 2002, relativa a un marco regulador común de las redes y los servicios de comunicaciones electrónicas (Directiva marco) (DO, L108, de 24 de abril de 2002, p. 33); en el mismo Diario Oficial, la Directiva 2002/20/CE del Parlamento Europeo y del Consejo, de 7 de marzo de 2002, relativa a la autorización de redes y servicios de comunicaciones electrónicas (Directiva de autorizaciones); la Directiva 2002/19/CE del Parlamento Europeo y del Consejo, de 7 de marzo de 2002, relativa al acceso a las redes de comunicaciones electrónicas y recursos asociados, y a su interconexión (Directiva de acceso); y la Directiva 2002/22/ CE del Parlamento Europeo y del Consejo, de 7 de marzo de 2002, relativa al servicio universal y los derechos de los usuarios en relación con las redes y los servicios de comunicaciones electrónicas (Directiva de servicio universal); la Directiva 2002/58/CE del Parlamento Europeo y del Consejo, de 12 de julio de 2002, relativa al tratamiento de los datos personales y a la protección de la intimidad en el sector de las comunicaciones electrónicas (Directiva sobre la privacidad y las comunicaciones electrónicas) (DO, L201, de 31.7.2002), y la Decisión 676/2002/CE del Parlamento Europeo y del Consejo, de 7 de marzo de 2002, sobre un marco regulador de la política del espectro radioeléctrico en la Comunidad Europea (Decisión espectro radioeléctrico) (DO, L108, de 24.4.2002). Este marco regulatorio se completa con la Directiva 2002/77/CE de la Comisión, de 16 de septiembre de 2002, relativa a la competencia en los mercados de redes y servicios de comunicaciones electrónicas (DO, L249, de 17.9.2002), aprobada en el marco del artículo 86.3 TCE". MATILDE CARLÓN RUIZ, Régimen jurídico de las telecomunicaciones. Una perspectiva convergente en el Estado de las autonomías, Madrid: La Ley, 2000, pp. 79-112.

50 Véase Resolución de la Subsecretaría del Ministerio de Obras Públicas y Transportes de 14 de enero de 1992, por la que se dispone la publicación del contrato del Estado con "Telefónica de España, Sociedad Anónima" (BOE de 23 de enero de 1992), cuyo objeto 
No obstante, esta liberalización de sectores estratégicos impulsada por la Unión Europea no lleva ataviada que los poderes públicos, y especialmente las Administraciones públicas, como garantes de los intereses generales (ex artículo 103.1 CE) se desentiendan del cariz prestacional y de los rasgos de esencialidad que determinados "servicios de interés económico general" poseen a la hora de garantizar la cohesión social y territorial ${ }^{52}$. Justamente, es ese marcado carácter de esencialidad respecto de las necesidades básicas de la ciudadanía, el que ha propiciado que el acervo comunitario ${ }^{53}$ haya terminado por contemplar una serie de excepciones al principio estructural de libre competencia, donde la intervención de los poderes públicos se concibe como una herramienta indispensable para garantizar unos estándares mínimos de prestación de aquellos servicios calificados como "de interés (económico) general", injerencia sin la cual difícilmente se podría alcanzar el acceso del conjunto de la ciudadanía a unos servicios esenciales

Esta "nueva" técnica de servicio ha permitido dotar de pasmosa actualidad y especial transcendencia una vez más a los viejos postulados que, conforme a las teorías de la Escuela de Burdeos ${ }^{54}$, se escondían tras la lógica del servicio público clásico: proteger la solidaridad y la interdependencia social

no es otro que el de regular la prestación en gestión indirecta, mediante concesión administrativa, de los servicios finales y portadores de telecomunicación.

51 Término comunitario acuñado originalmente en el conocido artículo 86.2 del Tratado Constitutivo de la Comunidad Europea y, sucesivamente, en el artículo 16, introducido por el Tratado de Maastricht, así como en el artículo 36 de la Carta de los Derechos Fundamentales de la Unión Europea. Véase TOMÁS DE LA QUADRA-SALCEDO, Liberalización de las telecomunicaciones, servicio público y Constitución económica europea, Madrid: Centro de Estudios Constitucionales, 1995.

52 La cohesión social y territorial constituye el fundamento común de todos los servicios de interés general. El propio Tratado Constitutivo, desde la modificación que introdujo el Tratado de Ámsterdam, conecta estos servicios con la promoción de estos aspectos (artículo 6). En estos momentos, el servicio universal de telecomunicaciones satisface, sobre todo, necesidades sociales. Cfr. Elisenda Malaret García, "Servicios públicos, funciones públicas, garantías de los derechos de los ciudadanos: Perennidad de las necesidades, transformación del contexto", Revista de Administración Pública, n. ${ }^{\circ} 145,1998$, pp. 80 y ss.

53 La STJue Corbeau, de 19 de mayo de 1993, y STJUE Almelo, de 27 de abril de 1994 subrayan la peculiaridad de estos servicios y la posibilidad de derogar los principios de libre competencia para atender a misiones como el servicio público o universal.

54 Si algo caracteriza la obra del gran jurista francés es su firme convicción de que el derecho debía adecuarse a la realidad que estaba llamada a regir para ordenarla racionalmente de acuerdo con la función social que debía realizar, la solidaridad o interdependencia social, a través de servicios públicos. Véase JaIme RodríGueZ-Arana MuÑOZ, "Sobre Las transformaciones del derecho público de León Duguit", p. 62. 
utilizando la actividad prestacional como elemento vehicular ${ }^{55}$. Todo ello, ha propiciado que, en los últimos años, numerosos teóricos y académicos hayan propugnado una vuelta a Duguit, si bien, como indica acertadamente Martín Rebollo, no en el sentido de volver a las técnicas del servicio público, sino a "la idea larvada que en ellas se albergaba, que no era otra que la idea de solidaridad social plasmada en el Estado que debe asumir las necesidades e intereses colectivos ${ }^{\prime \prime 5}$.

Esta premisa, unida al advenimiento del Estado garante ${ }^{57}$, entendiendo este como la reformulación del aparato administrativo orientada a impulsar el protagonismo de la sociedad y el sector privado, en detrimento de la influencia del poder público, y a garantizar que dicha actuación del sector privado se adecue a los intereses generales en juego establecidos en virtud del ordenamiento jurídico; constituyen para el medio rural ${ }^{58}$ el billete de ida necesario para subirse al último tren con destino a la sociedad digital ${ }^{59}$.

55 Si bien es cierto que, en la actualidad, la intervención pública para la garantía de determinadas prestaciones a todos los ciudadanos (artículo 128.2 CE) solo se justifica en aquellos supuestos en que la misma sea estrictamente imprescindible para no hurtar espacios a la libre competencia.

56 Véase Luis Martín Rebollo, "De nuevo sobre el servicio público: Planteamientos ideológicos y funcionalidad técnica", Revista de Administración Pública, vol. 3, n. ${ }^{\circ}$ 100-102, 1983, pp. 2496-2502. La misma opinión fue sostenida por Carmen CHINCHILla MARín, "Servicio público: ¿Crisis o renovación?", en Régimen jurídico de los servicios públicos, Madrid: Consejo General del Poder Judicial, 1997, p. 74.

57 En torno a esta cuestión cobran especial relevancia las palabras de Esteve Pardo, el cual concibe el tránsito del Estado prestacional al Estado garante de la siguiente forma: "La principal función a desarrollar entonces por el Estado y su aparato administrativo que se repliega, dejando a la sociedad y al sector privado el protagonismo gestor en muchos frentes de la acción pública, parece que habría de ser una función de garantía, asegurando, garantizando que en esa gestión y actuación del sector privado se atienden los intereses generales comprometidos y se alcanzan los objetivos y requerimientos que marcan la Constitución y las leyes. Esta nueva posición, este importante cometido, confiere al Estado una seña de identidad que lo redefine y caracteriza como Estado garante, tal como se conoce ya en Europa". José EsteVE PARDO, "La Administración garante. Una aproximación", Revista de Administración Pública, n. ${ }^{\circ}$ 197, 2015, p. 20.

58 La Ley 45/2007, de 13 de diciembre, de desarrollo sostenible del medio rural (LDSMR), ya recogía desde su preámbulo el carácter estratégico de las telecomunicaciones como presupuesto indispensable para favorecer y dinamizar la actividad económica de las áreas rurales, así como para incrementar la calidad de servicios esenciales, mediante el impulso de nuevas modalidades de prestación de servicios como la telemedicina (artículo 30 de LDSMR).

59 Entre las cuestiones que suscitan mayor preocupación e interés en el momento actual es ofrecer una solución para conseguir que el mundo rural consiga entrar en el mundo digital. Véase MAGDalena SuÁrez OJedA, "Smart cities, smart villages y acción pública", en Tomás de la Quadra-Salcedo y José Luis Piñar Mañas (dirs.), Sociedad digital y derecbo, Madrid: Boletín Oficial del Estado, 2018, p. 921. Ciertamente, el impulso de la innovación fomenta un atractivo diálogo entre la tradición y la modernidad muy fecundo, 


\subsection{LA IMPOSICIÓN DE OBLIGACIONES DE SERVICIO UNIVERSAL COMO PRESUPUESTO PARA GARANTIZAR EL ACCESO A LAS TELECOMUNICACIONES EN LAS ÁREAS RURALES}

Clarificadas las nuevas implicaciones que posee la ordenación vigente de la actividad prestacional de las Administraciones públicas, y sin perder de vista las exigencias normativas introducidas por el derecho comunitario, conviene analizar los instrumentos jurídico-administrativos diseñados por el legislador con la finalidad de equilibrar la tensión entre el interés público (y la satisfacción de los intereses generales) y los intereses privados que se concitan en los servicios de interés económico general (SIEG) ${ }^{60}$.

Así, el nuevo modelo de intervención pública tiene como instrumento principal "la imposición de cargas de servicio público a los operadores privados. A fin de que este modelo garantice la satisfacción del interés general al tiempo que sea compatible con las normas comunitarias, se debe realizar un ejercicio de máxima concreción en la definición del contenido del interés general, de las obligaciones a imponer a los operadores privados, de los instrumentos de financiación de las actividades impuestas a los operadores privados, y de los instrumentos de control del cumplimiento de las obligaciones" 61.

De esta forma, el título II de la Ley 9/2014, de 9 de mayo, Ley General de Telecomunicaciones (LGTel), contiene el régimen jurídico básico de la explotación de redes y la prestación de servicios de comunicaciones electrónicas ${ }^{62}$.

que puede ser capital para revitalizar la España rural. Cfr. DAVID EDGERTON, Innovación y tradición. Historia de la tecnología moderna. Barcelona: Editorial Crítica, 2007.

60 Recuérdese que lo característico en relación a estos servicios es que los poderes públicos no hacen dejación de las responsabilidades que les corresponden para garantizar el interés general.

61 Véase Juan José Montero Pascual, "Las telecomunicaciones: servicios de interés general", p. 236.

62 Recuérdese que la disposición adicional $18 .{ }^{a}$ contempla de forma expresa la universalización de la banda ancha ultrarrápida, mediante el establecimiento de una estrategia nacional de redes ultrarrápidas que tenga como objetivo impulsar el despliegue de redes de acceso ultrarrápido a la banda ancha, tanto fijo como móvil, de cara a lograr su universalización, así como fomentar su adopción por ciudadanos, empresas y administraciones, para garantizar la cohesión social y territorial en colaboración con las administraciones territoriales. Conforme a la redacción literal del precepto, en la ejecución de dicha estrategia "se podrán incluir medidas como la realización anual de convocatorias públicas de ayudas para la extensión de la cobertura de la banda ancha ultrarrápida que, bajo el principio de neutralidad tecnológica, doten de cobertura a zonas en las que no existe oferta y en las que no esté prevista en el corto plazo, en particular, con el objetivo de permitir acortar plazos de conexión y abaratar costes en núcleos rurales de difícil orografía y baja densidad de población. Estas convocatorias públicas garantizarán que las ayudas cubrirán solo un porcentaje de la inversión, que las ayudas se adjudicarán en régimen de concurrencia competitiva, y que la necesidad 
De conformidad con su artículo 2.1, las telecomunicaciones se califican como servicios de interés general que se prestan en régimen de libre competencia. De tal forma, solamente tendrán la consideración de servicio público o estarán sometidos a obligaciones de servicio público aquellos servicios de telecomunicaciones destinados a la defensa nacional, la seguridad pública, la seguridad vial y la protección civil, así como los restantes servicios contemplados en el título III de la norma, a cuyo análisis nos referiremos más adelante.

Ahora bien, la despublicatio ${ }^{63}$ de las comunicaciones electrónicas no implica la inobservancia o inexistencia de objetivos de interés público ${ }^{64}$, algo que se establece con rotundidad en el artículo 3 LGTel. De esta forma, entre los objetivos de la ley encontramos los siguientes:

a. Desarrollar la economía y el empleo digital, promover el desarrollo del sector de las telecomunicaciones y de todos los nuevos servicios digitales que las nuevas redes ultrarrápidas permiten, impulsando la cohesión social y territorial mediante la mejora y extensión de las redes, así como la prestación de los servicios de comunicaciones electrónicas y el suministro de los recursos asociados a ellas.

b. Promover el despliegue de redes y la prestación de servicios de comunicaciones electrónicas, fomentando la conectividad y la interoperabilidad extremo a extremo y su acceso, en condiciones de igualdad y no discriminación.

c. Fomentar, en la medida de lo posible, la neutralidad tecnológica en la regulación.

d. Garantizar el cumplimiento de las obligaciones de servicio público en la explotación de redes y la prestación de servicios de comunicaciones

de la ayuda se encuentra justificada en la existencia de un déficit comercial a corto o medio plazo que impide la ejecución del proyecto dada su baja rentabilidad, y contemple mecanismos para evitar una posible sobre compensación". En desarrollo de dicho precepto normativo nos encontramos el Real Decreto 462/2015, de 5 de junio, por el que se regulan instrumentos y procedimientos de coordinación entre diferentes $\mathrm{Ad}$ ministraciones públicas en materia de ayudas públicas dirigidas a favorecer el impulso de la sociedad de la información mediante el fomento de la oferta y disponibilidad de redes de banda ancha. Solamente en 2019, el Gobierno concedió un total de $140 \mathrm{mi}$ llones de euros a nivel nacional en ayudas públicas del programa PEBA-NGA para que los operadores aceleren el despliegue de redes de más de $100 \mathrm{Mbps}$ en zonas que, de otra manera, no recibirían esa cobertura al no resultar rentable para los operadores.

63 Véase José Luis MARTíneZ LóPeZ-MuÑIZ, "La publicatio de recursos y servicios", en AA. VV., Estudios de derecho público. Libro-bomenaje a Sebastián Martín-Retortillo, Madrid: Civitas, 2003, pp. 687-718.

64 Véase Gloria Calvo Díaz, "Ayudas de Estado en telecomunicaciones: El wifi municipal", Cuadernos de Derecho Local, n. ${ }^{\circ} 23,2010$, p. 125. 
electrónicas a las que se refiere el título III, en especial las de servicio universal.

e. Defender los intereses de los usuarios ${ }^{65}$, asegurando su derecho al acceso a los servicios de comunicaciones electrónicas en condiciones adecuadas de elección, precio y buena calidad, promoviendo la capacidad de los usuarios finales para acceder y distribuir la información o utilizar las aplicaciones y los servicios de su elección, en particular a través de un acceso abierto a internet. En la prestación de estos servicios deben salvaguardarse los imperativos constitucionales de no discriminación, de respeto a los derechos al honor y a la intimidad, la protección a la juventud y a la infancia, la protección de los datos personales y el secreto en las comunicaciones.

f. Salvaguardar y proteger en los mercados de telecomunicaciones la satisfacción de las necesidades de grupos sociales específicos, las personas con discapacidad, las personas mayores, las personas en situación de dependencia y los usuarios con necesidades sociales especiales, atendiendo a los principios de igualdad de oportunidades y no discriminación. En lo relativo al acceso a los servicios de comunicaciones electrónicas de las personas en situación de dependencia, se fomentará el cumplimiento de las normas o las especificaciones pertinentes relativas a normalización técnica publicadas de acuerdo con la normativa comunitaria.

g. Facilitar el acceso de los usuarios con discapacidad a los servicios de comunicaciones electrónicas y al uso de equipos terminales.

Con la finalidad de sentar las bases jurídicas pertinentes para garantizar "la existencia de servicios de comunicaciones electrónicas disponibles al público, de adecuada calidad en todo el territorio nacional a través de una competencia y una libertad de elección reales, y hacer frente a las circunstancias en que las necesidades de los usuarios finales no se vean atendidas de manera satisfactoria por el mercado"66, el título III de la Ley 9/2014, de 9 de mayo, prevé el establecimiento de un régimen de obligaciones de servicio público, distinguiendo dentro de estas dos modalidades diferenciadas de cargas jurídico-administrativas (artículo 24 LGTel): (1) obligaciones de servicio universal; y (2) obligaciones de servicio público impuestas por razones de interés general ${ }^{67}$. del usuario de los servicios de comunicaciones electrónicas.

66 Cfr. artículo 23.1 de la Ley 9/2014, de 9 de mayo, General de Telecomunicaciones.

67 Conforme a lo establecido en el artículo 28 LGTel, el Gobierno podrá, por necesidades de la defensa nacional, de la seguridad pública, de la seguridad vial o de los servicios 
A los efectos de la cuestión que aquí nos ocupa, debe entenderse en todo caso por obligaciones de servicio universal ${ }^{68}$ el conjunto definido de servicios cuya prestación se garantiza para todos los usuarios finales con independencia de su localización geográfica, con una calidad determinada y a un precio asequible (artículo 25.1 LGTel). Para dotar de efectividad tales obligaciones, en aquellos supuestos en los que el mercado y la libre competencia no garanticen la prestación de cualquiera de los elementos integrantes del servicio universal -como ocurre en el caso concreto de la desconexión digital de la España rural-, el régimen jurídico vigente establece la posibilidad de que la Administración general del Estado designe mediante real decreto uno o más operadores capaces de garantizar la prestación eficiente de dichos elementos del servicio universal, de manera que quede cubierta la totalidad del territorio nacional. A estos efectos podrán designarse ${ }^{69}$ operadores diferentes para la

que afecten a la seguridad de las personas o a la protección civil, imponer otras obligaciones de servicio público distintas de las de servicio universal a los operadores. Así mismo, podrá imponer otras obligaciones de servicio público, previo informe de la Comisión Nacional de los Mercados y la Competencia, así como de la Administración territorial competente, cuando así lo indiquen razones de cohesión territorial, razones de extensión del uso de nuevos servicios y tecnologías, en especial a la sanidad, a la educación, a la acción social y a la cultura; por la necesidad de facilitar la comunicación entre determinados colectivos que se encuentren en circunstancias especiales y estén insuficientemente atendidos con la finalidad de garantizar la suficiencia de su oferta así como por la necesidad de facilitar la disponibilidad de servicios que comporten la acreditación de fehaciente del contenido del mensaje remitido o de su remisión o recepción.

68 Bajo esta fórmula se pretende cubrir las carencias del mercado para prestar servicios que se consideran esenciales para todos los ciudadanos y que, por ello, no pueden depender del juego de la oferta y la demanda ni del ánimo de lucro. El servicio universal como la obligación de servicio público más importante de todas, representa el estándar comunitario en el acceso a un conjunto de prestaciones básicas previamente definidas, con una calidad suficiente, ofertado en todo el territorio a un precio razonable y a todos los usuarios, con independencia de cuál sea el operador que contraten y de cuáles las circunstancias geográficas y económicas en las que se desarrolla la oferta, premisas que en el supuesto concreto de la extensión de las telecomunicaciones en las áreas rurales los prestadores de servicios en red han incumplido de manera sistemática y reiterada en el tiempo, gracias a la connivencia del conjunto de las Administraciones públicas y a pesar de los cuantiosos incentivos económicos percibidos a costa del erario público.

69 El sistema de designación de operadores encargados de garantizar la prestación de los servicios, prestaciones y ofertas del servicio universal se establecerá mediante real decreto, con sujeción a los principios de eficiencia, objetividad, transparencia y no discriminación sin excluir a priori la designación de ninguna empresa. En todo caso, contemplará un mecanismo de licitación pública para dichos servicios, prestaciones y ofertas, garantía que deriva "del derecho de todos los operadores de iure a ser designados para prestar el servicio universal". Véase MATILDE CARLÓN RUIZ, "El servicio universal de telecomunicaciones", p. 64. 
prestación de diversos elementos del servicio universal y abarcar distintas zonas del territorio nacional ${ }^{70}$.

Sin embargo, y pese a la existencia de estas previsiones normativas, aún queda un largo y tortuoso camino por recorrer hasta alcanzar la plena digitalización de las áreas rurales que pueblan buena parte de la geografía del Estado español, algo que deriva en gran parte de la incapacidad de la Administración pública para garantizar los derechos subjetivos que forman parte de la institución del servicio universal. Y es que, como se ha demostrado en multitud de ocasiones, el sistema arbitrado para asegurar el cumplimiento del servicio universal de telecomunicaciones y tutelar los derechos e intereses de los consumidores ha resultado ser manifiestamente inefica $z^{71}$.

Este hecho condiciona enormemente la utilidad de la regulación pública de las telecomunicaciones, ya que "presenta deficiencias en su finalidad esencial, la de garantizar una serie de prestaciones básicas a los ciudadanos. No basta con establecer obligaciones de servicio público a los operadores ni con reconocer de forma más o menos programática derechos a los usuarios, ni con fiscalizar, con carácter general, el cumplimiento de estas obligaciones; es necesario también exigir su cumplimiento y efectividad en el caso concreto"72.

Urge, por tanto, no solamente revigorizar la idea de servicio universal, sino también repensar la efectividad y eficacia de la imposición de obligaciones de servicio universal a los grandes prestadores de servicios digitales como presupuesto para acabar con la desconexión tecnológica del medio rural.

En lo que se refiere a este último aspecto, reviste especial importancia la actividad tradicional de policía ${ }^{73}$ de la que están revestidas las diferentes

70 Recuérdese que el Ministerio de Energía, Turismo y Agenda Digital, mediante la Orden ETU/1973/2016, de 23 de diciembre, designa a Telefónica como operador encargado de la prestación del elemento del servicio universal relativo al suministro de la conexión a la red pública de comunicaciones electrónicas desde una ubicación fija y del relativo al servicio telefónico disponible al público a través de dichas conexiones, para todos los usuarios finales y con independencia de su localización geográfica, para un período comprendido entre el día 1 de enero de 2017 y el día 31 de diciembre de 2019, ambos inclusive.

71 En este sentido, Revuelta Pérez señala que la raíz de esta problemática puede deberse, en parte, a que "a diferencia de otros aspectos de las comunicaciones electrónicas, como la existencia de una competencia efectiva entre los operadores del sector, el derecho comunitario ha dejado la articulación del sistema de tutela de los usuarios mayoritariamente en manos de los Estados miembros, aduciendo el principio de subsidiariedad". Véase Inmaculada Revuelta PéRez, "La endeble garantía del servicio universal de telecomunicaciones", Revista de Administración Pública, n. ${ }^{\circ}$ 175, 2008, p. 427.

72 Ibid.

73 Podemos definir la actividad de policía "de modo provisional y sin intentar precisar demasiado, como el conjunto de medidas coactivas arbitradas por el derecho para que el particular ajuste su actividad a un fin de utilidad pública". Véase FERNANDO GARRIDO 
Administraciones públicas, al objeto de supervisar el cumplimiento de los principios aplicables a los servicios de interés económico general -continuidad, mutabilidad, igualdad, calidad y asequibilidad-, así como de las restantes obligaciones asumidas por los prestadores de servicios de comunicaciones electrónicas.

\section{LA AGENDA DIGITAL EUROPEA Y LOS PEQUEÑOS MUNICIPIOS}

La irrupción de las nuevas tecnologías ha propiciado numerosas e importantes transformaciones que alcanzan la totalidad de las esferas de nuestra vida cotidiana (familia, trabajo, educación, ocio, etc.). Como ha puesto de relieve la crisis sociosanitaria provocada por la COVID-19, la sociedad digital beneficia a todos los ciudadanos, y en especial a las personas que se encuentran en cualquier situación de vulnerabilidad como son las personas con discapacidad o mayores a las que puede ofrecer el apoyo necesario en su vida diaria ${ }^{74}$

Ciertamente, desde 1995, las tecnologías de la información y la comunicación han impulsado el aumento de la productividad y el crecimiento económico, así como la mejora sustancial de las condiciones de vida de la ciudadanía en la Unión Europea de una forma sin precedentes. Consciente de esta realidad, la Comisión Europea puso en marcha el mercado único digital en 2015 para hacer efectivas las principales propuestas legislativas, tales como el incremento del comercio electrónico, los derechos de autor, la privacidad electrónica, la avenencia de los derechos digitales ${ }^{75}$, la armonización de las normas sobre el IVA y la ciberseguridad.

FALLA, "Las transformaciones del concepto jurídico de policía administrativa", Revista de Administración Pública, n. ${ }^{\circ} 11,1953$, p. 11.

74 Cfr. María Pilar Munuera Gómez, "Agenda digital: e-Servicios sociales", Gestión y Análisis de Políticas Públicas, vol. 8, n. ${ }^{\circ} 16,2016$, pp. 27-46.

75 Recuérdese que la todopoderosa Ley Orgánica 3/2018, de 5 de diciembre, de protección de datos personales y garantía de los derechos digitales positiviza, entre sus disposiciones, el derecho de acceso universal a internet, tal y como reza en su artículo 81: "1. Todos tienen derecho a acceder a Internet independientemente de su condición personal, social, económica o geográfica. 2. Se garantizará un acceso universal, asequible, de calidad y no discriminatorio para toda la población. 3. El acceso a Internet de hombres y mujeres procurará la superación de la brecha de género tanto en el ámbito personal como laboral. 4. El acceso a Internet procurará la superación de la brecha generacional mediante acciones dirigidas a la formación y el acceso a las personas mayores. 5. La garantía efectiva del derecho de acceso a Internet atenderá la realidad específica de los entornos rurales. 6. El acceso a Internet deberá garantizar condiciones de igualdad para las personas que cuenten con necesidades especiales". 
Este compromiso se materializó a raíz de la Estrategia de Lisboa en la adopción de la Agenda Digital para Europa ${ }^{76}$, proyecto que fue concebido como una de las siete iniciativas emblemáticas de la Estrategia Europa $2020^{[77]}$ impulsadas por la Comisión y que nace con la vocación de definir la función capacitadora esencial que debe desempeñar el uso de las TIC para que Europa pueda hacer realidad sus ambiciosos objetivos para 2020. Esta iniciativa reviste, además, una importancia capital al objeto de garantizar un entorno digital seguro, abierto e imparcial, en la línea de lo establecido en la "Estrategia para el Mercado Único Digital", la cual se estructura en torno a tres pilares esenciales, que están íntima y estrechamente vinculados a nuestro objeto de estudio: (1) mejorar el acceso de los consumidores y las empresas a los bienes y servicios digitales en Europa, (2) crear las condiciones adecuadas para el éxito de los servicios y las redes digitales, y (3) aprovechar al máximo el potencial de crecimiento de la economía digital ${ }^{78}$.

El objetivo de esta Agenda, por tanto, no es otro que el de trazar un rumbo que permita maximizar el potencial económico y social de las TIC, y en particular de internet, como soporte esencial de la actividad económica y social, requisito imprescindible para combatir la desconexión digital de la España vacia(da).

Fruto de la importancia de esta cuestión, la Agenda Digital para Europa establece entre sus campos prioritarios de actuación el objetivo de garantizar la cobertura universal de la banda ancha con velocidades crecientes. Para ello, no solamente se detiene en reconocer el papel decisivo que la banda ancha inalámbrica (terrenal y satelital) puede desempeñar para garantizar la

76 La finalidad genérica de la agenda digital es obtener los beneficios económicos y sociales sostenibles que pueden derivar de un mercado digital único basado en una internet rápida y ultrarrápida y en unas aplicaciones interoperables. Cfr. COMISIÓN EUROPEA, Una agenda digital para Europa [COM(2010)245 final].

77 Cfr. Mercedes Caridad Sebastián, Ana María Morales García y Fátima López GARCía, "La estrategia Europa 2020 y la sociedad de la información como instrumentos de cohesión e integración en época de crisis. ¿Utopía o realidad?", Investigación Bibliotecológica, vol. 28, n. ${ }^{\circ} 64,2014$, pp. 101-115.

78 Recuérdese que si bien es cierto que los tratados no contienen disposiciones específicas relativas a las TIC, la Unión Europea puede emprender determinadas actuaciones en el marco de sus políticas sectoriales y horizontales, por ejemplo, en el ámbito de la política industrial (artículo 173 TFUE), la política de competencia (artículos 101 a 109 TFUE), la política comercial (artículos 206 y 207 TFUE), las redes transeuropeas (artículos 170 a 172 TFUE), la investigación y el desarrollo tecnológico y del espacio (artículos 179 a 190 TFUE), la aproximación de las legislaciones para mejorar el establecimiento y el funcionamiento del mercado interior (artículo 114 TFUE), la libre circulación de mercancías (artículos 28, 30 y 34 a 35 TFUE), la libre circulación de personas, servicios y capitales (artículos 45 a 66 TFUE), la educación, la formación profesional, la juventud y el deporte (artículos 165 y 166 TFUE), y la cultura (artículo 167 TFUE). Todos ellos son elementos clave de la Europa Digital. 
cobertura de todas las zonas, incluidas las regiones rurales y apartadas, sino que además establece la necesidad de promover una decidida intervención pública, sin la cual "se corre el riesgo de que los resultados no sean óptimos, concentrándose las redes rápidas de banda ancha en unas pocas zonas de alta densidad con costes de entrada importantes y precios elevados. Los beneficios colaterales que estas redes generan para la economía y la sociedad justifican unas políticas públicas que garanticen una cobertura universal de la banda ancha con velocidades crecientes"79.

Esta Agenda Digital para Europa ha encontrado su reflejo no solamente en el establecimiento de un marco común dentro del cual deban elaborarse las políticas nacionales y comunitarias encaminadas a abaratar el despliegue de la banda ancha en todo el territorio de la Unión Europea, sino garantizar una planificación y coordinación adecuadas entre los diferentes agentes implicados y aliviar las cargas administrativas que impiden o dificultan, de una u otra forma, la consecución de la plena conectividad del territorio europeo. Además, se ha traducido en la puesta en marcha de numerosas iniciativas tangibles e innovadoras orientadas a dotar de efectividad práctica el contenido del derecho digital de acceso universal a internet ${ }^{80}$.

Una de estas iniciativas pioneras la constituye el Programa WiFi4EU ${ }^{81}$, cuyo objetivo no es otro que el de proporcionar en toda la Unión Europea a residentes y visitantes acceso a internet de alta calidad a través de puntos gratuitos de acceso wifi ubicados en espacios públicos como parques, plazas, edificios administrativos, bibliotecas y centros de salud. Los bonos ${ }^{82}$ financiados por la Comisión Europea a través de esta iniciativa se conceden con el objetivo de ayudar a los municipios a instalar los puntos de acceso wifi en estos centros de la vida pública, utilizando los servicios de empresas de instalación especializadas.

Estos esfuerzos contrastan enormemente con la escasez de iniciativas propias que las diferentes instituciones nacionales han implementado para poner fin a la desconexión digital de las áreas rurales, algo especialmente llamativo en el caso castellanoleonés ${ }^{83}$, donde las políticas públicas orientadas

79 Cfr. COMISIÓn Europea, Una agenda digital para Europa [COM(2010)245 final].

80 Téngase en cuenta que la Resolución del Parlamento Europeo, de 5 de mayo, cuya ponente fue la eurodiputada Pilar del Castillo, afianza el derecho de todos los hogares de la Unión Europea a disponer de acceso de banda ancha a internet a precios competitivos, así como el desarrollo de un mercado único digital y la garantía de la neutralidad de la red.

81 Puede consultarse más información acerca de esta iniciativa en el enlace https://wifi4eu. ec.europa.eu/\#/home [consultado el 10 de enero de 2021].

82 El importe de cada bono asciende a $\$ 15.000$ euros.

83 De conformidad con los datos obrantes en la Secretaría de Estado para el Avance Digital, en Castilla y León hay 5.102 "zonas blancas", ranking encabezado por León (1.106), 
a tal fin se caracterizan por encontrarse en una constante y latente disyuntiva: inacción (brillan por su ausencia) o incapacidad (rara vez van más allá del papel mojado $)^{84}$.

\section{EMPRENDIMIENTO DIGITAL Y TELETRABAJO COMO PUNTA DE LANZA PARA PROMOVER EL ASENTAMIENTO DE POBLACIÓN EN EL MEDIO RURAL EN LA ERA POST COVID-19}

Como ha puesto de relieve la crisis sanitaria de la COVID-19, las áreas rurales son espacios resilientes, seguros, capaces de albergar una exuberante riqueza ambiental, patrimonial, cultural, etc., al tiempo que son el espacio idóneo para generar nuevas oportunidades de emprendimiento $y$, por qué no, para acoger también la deslocalización de la actividad laboral, empleando las nuevas tecnologías como punta de lanza.

El teletrabajo representa, por tanto, una oportunidad única para revitalizar, por un lado, las áreas rurales despobladas, en la medida en que permite al trabajador prestar sus obligaciones laborales a distancia, facilitando con ello el regreso de habitantes cualificados que tiempo atrás vieron como sus expectativas de promoción personal y profesional les obligaban a abandonar sus raíces, el asentamiento de nuevos pobladores o la dinamización de la economía rural. Y por otro, para poner en valor la necesidad de custodiar el territorio que representa el medio rural, cuestión esta última sobre la que nos gustaría detenernos, al menos, un instante.

En efecto, son muchas las personas que han visto en la crisis sociosanitaria la encrucijada idónea para iniciar o retomar su proyecto vital en la España

Burgos (1.062) y Salamanca (707). Las zonas blancas son áreas que no disponen de cobertura de redes de banda ancha de nueva generación ni previsión de tenerlas en un plazo de tres años. Esto se traduce en que 635.067 castellanos y leoneses (el equivalente a las ciudades de León, Valladolid, Soria y Burgos juntas) no tiene internet de alta velocidad, y que 141.510 personas ni siquiera dispongan de acceso a internet de $30 \mathrm{Mbps}$.

Un ejemplo de estas iniciativas de quiero y no puedo, lo encontramos en el caso de la Diputación de Salamanca, institución provincial que en el pleno ordinario de fecha 30 de octubre de 2019 aprobó destinar 6 millones de euros a la implantación de internet de banda ancha en los ayuntamientos de la provincia, partida presupuestaria de la que transcurrido más de un año no se ha ejecutado ni un solo euro. Paralelamente, otras Administraciones territoriales han impulsado sendas iniciativas, con similares cotas de éxito. Sin ir más lejos, la Junta de Castilla y León publicó en agosto de 2019 una convocatoria de subvenciones de 3 millones de euros para toda la comunidad con la finalidad de extender las redes de acceso a internet de alta velocidad a los habitantes de las zonas rurales más despobladas, destinadas a cubrir a los prestadores de servicios de telecomunicaciones hasta el $90 \%$ del coste total del proyecto. 
vacia(da). Sin embargo, esta tendencia positiva colisiona una vez más, casi de manera antagónica, con la realidad rural, donde la carencia de servicios esenciales $^{85}$, ya no solo las telecomunicaciones, marcan el día a día de los habitantes que, de manera estoica, permanecen en estas áreas despobladas, con la consiguiente afectación que esta situación produce sobre su esfera personal.

Ante esta tesitura, el teletrabajo representa una oportunidad fundamental no solamente para contrarrestar el saldo demográfico de las áreas rurales despobladas, sino también, y más importante todavía, para visibilizar la importancia cardinal de garantizar el acceso a la población a unos servicios esenciales de calidad en condiciones de igualdad, así como la urgencia de revalorizar el papel que las comunidades rurales juegan en nuestra sociedad actual. Estas son, en nuestra opinión, las principales enseñanzas que la unión de la COVID-19 y la aceleración de los procesos de digitalización y datificación han traído consigo, las cuales no deben menospreciar los poderes públicos a la hora de diseñar e impulsar los instrumentos necesarios para alcanzar un modelo de país social y territorialmente cohesionado, más justo e igualitario y comprometido con el desarrollo sostenible en todas sus facetas.

\section{CONCLUSIONES}

En nuestros días, garantizar el acceso de la ciudadanía y las empresas a los servicios de telecomunicaciones se ha convertido en el presupuesto indispensable para corregir el tradicional aislamiento que padecen los núcleos rurales, favorecer la cohesión económica y social, y alcanzar la ansiada vertebración del territorio. Ciertamente, aunque en la actualidad las telecomunicaciones distan enormemente de lo que antaño era un servicio público reservado y monopolístico, es necesario precisar que los intereses públicos en juego siguen imprimiendo un intenso carácter regulado que hace de las telecomunicaciones "servicios de interés económico general", categoría jurídica alumbrada por el derecho comunitario con la finalidad de equilibrar la tensión entre el interés público y los intereses privados que se concitan en este tipo de actividades económicas. Equilibrio que, por otro lado, implica reconocer rasgos de esencialidad en estas prestaciones respecto de las necesidades de los ciudadanos y que se traduce, principalmente, en un conjunto de limitaciones y de obligaciones para los operadores, entre las que

85 Un ejemplo de esta problemática lo encontramos en el cierre sistemático de oficinas de banca en el medio rural, con lo que ello implica para una población cada vez más envejecida, sin posibilidad de acceder a servicios de transporte y ante la ausencia de una red de cajeros automáticos. 
destacan la prestación de "obligaciones de servicio público" y la garantía de un "servicio universal".

Sin embargo, y pese a la existencia de estas previsiones normativas, aún queda un largo y tortuoso camino por recorrer hasta alcanzar la plena digitalización de las áreas rurales que pueblan buena parte de la geografía del Estado español, algo que deriva en gran medida de la incapacidad de la Administración pública para garantizar los derechos subjetivos que forman parte de la institución del servicio universal. Este hecho condiciona enormemente la utilidad de la regulación pública de las telecomunicaciones, ya que presenta deficiencias en su finalidad esencial, la de garantizar una serie de prestaciones básicas a los ciudadanos. No basta con establecer obligaciones de servicio público a los operadores ni con reconocer de forma más o menos programática derechos a los usuarios, ni con fiscalizar, con carácter general, el cumplimiento de estas obligaciones; es necesario también exigir su cumplimiento y efectividad en el caso concreto. Urge, por tanto, reconstruir la idea de servicio público universal y repensar la efectividad y eficacia de la imposición de obligaciones de servicio universal a los grandes prestadores de servicios digitales como presupuesto para acabar con la desconexión tecnológica del medio rural. Esta es, a nuestro entender, la clave de bóveda sobre la que debe erigirse el entramado de políticas públicas y actuaciones orientadas a remover los obstáculos que impiden la plena conectividad territorial, garantizando con ello el acceso al teletrabajo al conjunto de la población, independientemente del lugar de residencia, y abriendo una ventana de esperanza a la dinamización de las economías rurales, el asentamiento de nuevos pobladores y la revitalización, en definitiva, de los pueblos que integran la conocida por todos como España vaciada.

\section{BIBLIOGRAFÍA}

Altés Tárrega, Juan Antonio, y Sergio Yagüe Blanco. "A vueltas con la desconexión digital: eficacia y garantías de lege lata". Revista de Derecho del Trabajo y Protección Social, vol. 1, n. ${ }^{\circ} 2,2020$.

Bacigalupo Sagesse, Mariano. "El derecho público ante la privatización y liberalización de los servicios de interés general. ¿Repliegue o transformación?". Boletín de la Facultad de Derecbo de la UNED, n. ${ }^{\circ}$ 16, 2000.

Bello Paredes, Santiago Agustín. "Castilla y León vacía (vaciada). Esperando a Ulises". Revista de Estudios de la Administración Local y Autonómica, Nueva época, n. ${ }^{\circ} 13,2020$.

Blanco Romero, Asunción, y Gemma Cànoves Valiente. "El teletrabajo, calternativa para el mundo rural?". En IX Coloquio de Geografía Rural: Comunicaciones. 
Vitoria: Universidad del País Vasco, Departamento de Geografía, Prehistoria y Arqueología, 1998.

Buenaventura Calvo, Alfonso, y José luis Domínguez Álvarez. "¿Reinventarse o morir? El municipalismo como piedra angular del anhelado desarrollo rural sostenible. San Martín del Castañar, una referencia al sur de la provincia de Salamanca". En Marcos Matías Fernando Pablo y José Luis Domínguez Álvarez (dirs.), Rural Renaissance: Derecho y medio rural. Cizur Menor: Thomson Reuters-Aranzadi, 2020.

BUIRÁ CIPRÉS, JORDI. El teletrabajo. Entre el mito y la realidad. Barcelona: Ediciones Universitat Oberta de Catalunya, 2012.

Calvo Díaz, Gloria. "Ayudas de Estado en telecomunicaciones: El wifi municipal". Cuadernos de Derecho Local, n. ${ }^{\circ}$ 23, 2010.

Cánoves Valiente, Gemma, y Asunción Blanco Romero. "Teletrabajo, género y gentrificación o elitización en los espacios rurales: Nuevos usos y nuevos protagonistas. Los casos de Cataluña y Ardèche (Francia)". Geograpbicalia, n. ${ }^{\circ}$ 50, 2006.

Carlón Ruiz, Matilde. Régimen jurídico de las telecomunicaciones. Una perspectiva convergente en el Estado de las autonomías. Madrid: La Ley, 2000.

Carlón Ruiz, Matilde. "El servicio universal de telecomunicaciones". Revista de Administración Pública, n. ${ }^{\circ}$ 171, 2006.

Carlón Ruiz, Matilde. El servicio universal de telecomunicaciones. Cizur Menor: Thomson-Civitas, 2007.

Carrillo Donaire, Juan Antonio. "El servicio universal de telecomunicaciones". Revista de Administración Pública, n. ${ }^{\circ}$ 179, 2009.

Chinchilla Marín, Carmen. "Servicio público: ¿Crisis o renovación?". En Régimen jurídico de los servicios públicos. Madrid: Consejo General del Poder Judicial, 1997.

Colom Gorgues, AnTONiO. "Innovación organizacional y domesticación de Internet y las TIC en el mundo rural, con nuevas utilidades colectivas y sociales. La figura del Telecentro y el Teletrabajo". CIRIEC-España, n. . 49, 2004.

COMISIÓn EUROPEA. Le travail à domicile dans l'Union Européenne. Rapport du groupe de travail ad hoc. Bruselas: Comisión Europea, 1995.

COMISIÓn EUROPEA. Mejorar el acceso de las zonas rurales a las modernas tecnologías de la información y la comunicación (TIC) [COM(2009) 103 final].

COMISIÓn EUROPEA. Una agenda digital para Europa [COM(2010)245 final]. 
Comisionado del Gobierno Frente al Reto Demográfico. Directrices Generales de la Estrategia Nacional frente al Reto Demográfico. Madrid: CGFRD, 2019.

CONSEJO ECONÓMICO Y SOCIAL. El medio rural y su vertebración social y territorial. Informe 01/2018, aprobado en sesión ordinaria del Pleno de 24 de enero de 2018. Madrid: Consejo Económico y Social, 2018.

De la QuAdra-SAlCEDO, TOMÁS. Liberalización de las telecomunicaciones, servicio público y Constitución Económica Europea. Madrid: Centro de Estudios Constitucionales, 1995 .

Del Molino, Sergio. La España vacía: Viaje por un país que nunca fue. Madrid: Turner, 2016.

Del Romero Renau, Luis. Despoblación y abandono de la España rural. El imposible vencido. Valencia: Tirant lo Blanch Humanidades, 2018.

Domínguez Álvarez, José Luis. "El agotamiento de las políticas públicas relacionadas con el desarrollo rural". En Marcos Matías Fernando Pablo y José Luis Domínguez Álvarez (dirs.), Rural Renaissance, derecho y medio rural. Cizur Menor: Thomson Reuters-Aranzadi, 2020.

Domínguez Álvarez, José Luis. "El desigual acceso de la juventud rural a los servicios públicos: la necesidad de impulsar la educación en la España vaciada". Cuadernos de Investigación en Juventud, n. ${ }^{\circ}$ 8, 2020.

Domínguez Álvarez, JOSÉ LUIS. Comunidades discriminadas y territorios rurales abandonados. Políticas públicas y Derecho administrativo frente a la despoblación. Cizur Menor: Thomson Reuters, 2021.

Domínguez Álvarez, José Luis. "El impulso del teletrabajo en la España vacia(da) en la era post COVID-19: Del mito al logos". En Juan Francisco Rodríguez Ayuso y Elena Atienza Matías (coords.), El nuevo marco legal del teletrabajo en España: Presente y futuro, una aproximación multidisciplinar. Madrid: Wolters Kluwer, 2021.

EDGERTON, DAVID. Innovación y tradición. Historia de la tecnología moderna. Barcelona: Crítica, 2007.

Esteve PARdo, José. "La Administración garante. Una aproximación". Revista de Administración Pública, n. ${ }^{\circ}$ 197, 2015.

FERnÁndez RodrígueZ, TOMÁs RAmÓn. "Del servicio público a la liberalización desde 1950 hasta hoy". Revista de Administración Pública, n. ${ }^{\circ}$ 150, 1999.

FERnAndo PABlo, Marcos Matías. "Devolver el alma a los pueblos: El encuentro Rural Renaissance". Ars Iuris Salmanticensis, vol. 9, n. ${ }^{\circ}$ 2, 2019. 
GARRIDO FALla, FERnANDO. "Las transformaciones del concepto jurídico de policía administrativa". Revista de Administración Pública, n. ${ }^{\circ} 11,1953$.

Gray, Mike, Noel Hodson y Gil Gordon. El teletrabajo. Madrid: BT Telecomunicaciones-ECTF-Fundación Universidad Empresa, 1995.

InSTITUTO NACIONAL DE ESTADíSTICA. Encuesta sobre Equipamiento y Uso de Tecnologías de Información y Comunicación en los Hogares 2019. Madrid: Instituto Nacional de Estadística, 2020.

Malaret García, Elisenda. "Servicios públicos, funciones públicas, garantías de los derechos de los ciudadanos: perennidad de las necesidades, transformación del contexto". Revista de Administración Pública, n. ${ }^{\circ}$ 145, 1998.

MARTín, ESTRELLA. "El acceso a internet, un servicio obligatorio en todo el medio rural". Vida Rural, n. ${ }^{\circ} 156,2002$.

Martín Rebollo, Luis. "De nuevo sobre el servicio público: planteamientos ideológicos y funcionalidad técnica". Revista de Administración Pública, vol. 3, n. ${ }^{\circ}$ $100-102,1983$.

Martínez LÓPEZ-MUÑ̃z, José LUIS. "La publicatio de recursos y servicios". En VV. AA., Estudios de derecho público. Libro-bomenaje a Sebastián Martín-Retortillo. Madrid: Civitas, 2003.

Ministerio de Asuntos ECOnÓmiCOS Y TRANSFORMACiÓn DiGitAl. España digital 2025, Madrid, 2020.

Molina NavarRete, CRistóbal. "Jornada laboral y tecnologías de la infocomunicación: "Desconexión digital", garantía del derecho al descanso". Temas laborales, n. ${ }^{\circ} 138,2017$.

Montero Pascual, Juan José. "Las telecomunicaciones: servicios de interés general". Revista de Derecho de la Unión Europea, n. ${ }^{\circ}$ 7, 2004.

Munuera Gómez, PIlar. "Agenda digital: e-Servicios sociales". Gestión y Análisis de Políticas Públicas, vol. 8, n. ${ }^{\circ} 16,2016$.

Parejo Alfonso, Luciano. "Servicios públicos y servicios de interés general: La renovada actualidad de los primeros". Revista de Derecho de la Unión Europea, n. ${ }^{\circ} 7,2004$.

Revuelta PÉRez, InMaCulada. "La endeble garantía del servicio universal de telecomunicaciones". Revista de Administración Pública, n. ${ }^{\circ}$ 175, 2008. 
Rico Nieto, JAVIER. "La digitalización es una pieza clave en la lucha contra la despoblación". Desarrollo rural y sostenible, n. ${ }^{\circ} 43,2020$.

RodríGUEZ-ARAnA MUÑoz, JAIME. "Servicio público y derecho comunitario europeo". Revista de Direito Administrativo \& Constitucional, vol. 4, n. ${ }^{\circ}$ 17, 2007.

Rodríguez-Arana Muñoz, Jaime. "Sobre Las transformaciones del derecho público de León Duguit", Revista de Administración Pública, n. ${ }^{\circ}$ 190, 2013.

Ruíz GonzÁlez, Carlota María. "La desconexión digital como garantía y herramienta de conclusión de la jornada laboral. Su necesaria concreción en tiempos de COVID-19". Revista General de Derecho del Trabajo y de la Seguridad Social, n. ${ }^{\circ} 56,2020$.

SAMPEDro Gallego, Rosario. "Conciliación de la vida familiar y laboral en el medio rural: género, trabajo invisible e 'idilio rural'". En AA. VV., Mujeres rurales: Estudios multidisciplinares de género. Salamanca: Ediciones Universidad de Salamanca, 2014.

SÁnchez Morón, Miguel. Derecho administrativo. Parte general. Madrid: Tecnos, 2018.

Sebastián, Mercedes Caridad, Ana María Morales García y Fátima lópez GARCÍA. "La estrategia Europa 2020 y la sociedad de la información como instrumentos de cohesión e integración en época de crisis. ¿Utopía o realidad?". Investigación Bibliotecológica, vol. 28, n. ${ }^{\circ}$ 64, 2014, pp. 101-115.

Sosa Wagner, Francisco. La gestión de los servicios públicos locales, 7. a ed. Madrid: Civitas, 2008.

SuÁrez OjedA, MagdalenA. "Smart cities, smart villages y acción pública". En Tomás de la Quadra-Salcedo y José Luis Piñar Mañas (dirs.), Sociedad digital y derecho. Madrid: Boletín Oficial del Estado, 2018.

TALÉnS Visconti, EDUARDO. "La desconexión digital en el ámbito laboral: un deber empresarial y una nueva oportunidad de cambio para la negociación colectiva". Revista de Información Laboral, n. ${ }^{\circ}$ 4, 2018. 